\title{
Processamento de imagem digital (PID) como meio de análise, documentação e monitorização da corrosão do aço de carbono aplicado na escultura de Gonçalo Jardim
}

\author{
Ana Sofia Alvarez, João Linhares, Ana Bailão
}

\begin{abstract}
Resumo: O presente artigo pretende dar a conhecer um método de monitorização não invasiva do processo de corrosão da escultura de aço de Gonçalo Jardim, através do sistema de processamento de imagem digital. Esta investigação teve como principal objetivo desenvolver um algoritmo que faça o tratamento da informação de várias funções locais da morfologia da corrosão, através da extração de parâmetros quantitativos da imagem que exprimam essa informação. Para este efeito foi calculado o valor médio absoluto da entropia das imagens, que avalia a evolução da morfologia da corrosão da obra a longo prazo, de modo a documentá-la e analisar se há manutenção ou aumento da corrosão com o decorrer do tempo e, neste último caso, em que proporção
\end{abstract}

Palavras-chave: processamento de imagem digital, entropia, monitorização, corrosão, escultura em aço

\section{Procesamiento de imagen digital (PID) como medio de análisis, documentación y monitorización de la corrosión del acero de carbono aplicado en la escultura de Gonçalo Jardim}

Resumen: El presente artículo pretende dar a conocer un método de monitorización no invasiva del proceso de corrosión de la escultura de acero de Gonçalo Jardim, a través del sistema de procesamiento de imagen digital. Esta investigación tiene como principal objetivo desarrollar un algoritmo que trate la información de varias funciones locales de la morfología de la corrosión, a través de la extracción de parámetros cuantitativos de la imagen que expresan esa información. Para este efecto se ha calculado el valor medio absoluto de la entropía de las imágenes, que evalúa la evolución de la morfología de la corrosión de la obra a largo plazo, para documentarla y analizar si se mantiene o aumenta de la corrosión con el transcurso del tiempo y, en este último caso, en qué proporción.

Palabras clave: procesamiento de imagen digital, entropía, monitoreo, corrosión, escultura en acero

Digital image processing (DIP) as a means of analysis, documentation and monitoring of the corrosion of the carbon steel applied in the sculpture of Gonçalo Jardim

\begin{abstract}
This article aims to present a non - invasive monitoring of the corrosion process of Gonçalo Jardim 's steel sculpture through the digital image processing system. This research had as main objective to develop an algorithm that treats the information of several local functions of the morphology of the corrosion, through the extraction of quantitative parameters of the image that express this information. For this purpose, the absolute mean value of the entropy of the images was calculated, which evaluates the evolution of the morphology of the corrosion of the sculpture in long term, in order to document it and to analyse if there is maintenance or increase of the corrosion with the passage of time and, in the latter case, in what proportion.
\end{abstract}

Keywords: digital image processing, entropy, monitoring, corrosion, steel sculpture 


\section{Introdução}

Este artigo apresenta um método de monitorização da corrosão de uma escultura de aço do artista Gonçalo Jardim. Com o intuito de analisar e controlar a evolução da deterioração material no tempo desenvolveu-se um sistema de processamento de imagem digital (PID) baseado na caracterização morfológica de imagens fotográficas.

Para a generalidade dos metais, a corrosão resulta da tendência do material em voltar ao seu estado de energia mais baixo, sob a forma de óxido de ferro hidratado, que ocorre quando este é combinado com o oxigénio e a água, presentes nos ambientes naturais (AMS International 2000:1). No estudo desenvolvido pela NACE International (2016) ficou patente que os custos globais da corrosão contribuem para cerca de $2,5 \%$ a $4 \%$ do PIB de cada país, dependendo do grau de industrialização, e que cerca de $50 \%$ destes custos são provocados pela corrosão atmosférica. A necessidade de detetar e acompanhar esta deterioração torna-se então importante, uma vez que possibilita prever a durabilidade do material e definir estratégias de manutenção mediante os valores registados.

O sistema PID é conhecido pela manipulação de imagens digitais onde se convertem imagens visuais em dados numéricos organizados em matrizes. A organização em matriz permite ordenar os pixéis da imagem mantendo a sua posição espacial associada à correspondente informação cromática. A partir destes dados numéricos e através de processamento digital e algoritmos computacionais é possível extrair informações ou atributos característicos da imagem (Esquef et al. 2003:1). É um sistema que faz um pré-tratamento digital da imagem, segmenta a informação - extrai os "objetos" do "fundo" da imagem - e determina a grandeza de cada "objeto" (área, perímetro, forma, descrição estrutural, topologia, entre outros). Além disso, permite reconhecer os "objetos" e fazer uma análise quantitativa, que associa as grandezas ao problema, sendo capaz de determinar funções de correlação espacial ou temporal e de analisar sequências de imagens (Albuquerque 2001:4). Trata-se de uma técnica eficaz e de baixo custo, de características não invasivas e de rápida resposta, que tem sido aplicada como uma alternativa para a avaliação da corrosão, a partir das características morfológicas da cor, da textura e da forma.

Este sistema, associado a processos de análise matemática, foi utilizado por Choi e Kim (2004) como um método automatizado e probabilístico para classificar e detetar a corrosão de uma superfície. Partindo de uma descrição cromática HSI (formado pelos atributos Hue - matiz-; Saturation - saturação-; Intensity - intensidade) calculou a cor da corrosão utilizando como base um modelo prédefinido. Foi ainda utilizada a matriz de coocorrência para a descrição das características da textura da corrosão, obtida pela relação tridimensional entre os graus de luminosidade (I) da imagem analisada. Por fim, para agrupar e identificar as regiões afetadas pela corrosão fizeram uso do processo de escalonamento multidimensional (MultiDimensional Scaling-MDS). Semelhante a esse estudo, Bento et al. (2009) aplicaram a matriz de coocorrência utilizando níveis cinza, para a deteção de mudanças de textura nas superfícies metálicas, e recorreram ao método de mapeamento autoorganizável (Self-Organized Map - SOM) para classificar as imagens como oxidadas e não oxidadas.

Com a possibilidade de calcular automaticamente a percentagem da corrosão numa determinada imagem de superfície, Ghanta et al. (2011) introduziram a ferramenta de transformada de Wavelet como método de deteção da corrosão, para reunir as propriedades de textura de uma imagem. Nesse estudo, o algoritmo proposto consistiu numa fase de ensaio e numa fase de deteção, que fez uso de imagens com e sem oxidação, onde a técnica de correlação cruzada foi aplicada para determinar as áreas de potencial corrosão. O programa utilizado apresentou apenas $52 \%$ de eficácia na classificação de imagens corroídas. Esta limitação foi posteriormente resolvida pela técnica apresentada por Diaz et al. (2017) com uma taxa de $90 \%$ de sucesso, recorrendo à função de thresholding, à segmentação da textura e ao reconhecimento de contornos no processamento da imagem.

Na presente investigação, o sistema PID foi utilizado com o propósito de monitorizar, analisar e documentar a deterioração do material da escultura de aço de Gonçalo Jardim. O processo foi fundamentado nos métodos de deteção e de quantificação da corrosão propostos por Diaz et al. (2017) e por Yidong et al. (2017).

\section{Aplicação de PID}

\section{- Software}

O software MatLab ${ }^{\circledR}$ (MatWorks, Natick, MA, USA) foi o selecionado para a elaboração do algoritmo. Trata-se de um sistema interativo de programação, cujo elemento de dados é uma matriz. É capaz de efetuar cálculos numéricos, construir gráficos, bem como analisar e processar estas informações (MathWorks 2005:1.2).

\section{- Aquisição de imagens}

No que importa à recolha de imagem da superfície morfológica da camada de corrosão, é necessário que seja feita em diferentes zonas da superfície, com períodos de tempo variados entre capturas, e que obedeça a condições físicas idênticas. Assim, os resultados serão mais eficazes se as imagens forem capturadas com a mesma câmara, fixada num tripé e sob as mesmas condições fotográficas, e se a distância destes equipamentos para o objeto analisado for a mesma em todos os momentos. Além disso, idealmente, a iluminação deve ser sempre igual e uniforme, de maneira a facultar todas as características da morfologia das superfícies. 


\section{- Algoritmo}

Oalgoritmo proposto permite detetar alterações morfológicas, traduzidas em corrosão, e quantificar a sua evolução. A entropia associada a cada imagem é estimada medindo as alterações espaciais locais, calculando o VAM (valor de alteração morfológica), que calcula o valor médio absoluto da entropia de cada imagem a partir das variações locais:

$$
V A M=\frac{1}{c . l} \sum_{\substack{i=1: c \\ j=1: l}}\left|J_{i j}-I_{i j}\right|
$$

Em que $J$ é a imagem a analisar, / é a imagem inicial de referência assumindo o tempo inicial ( $t=$ ano 0$)$, $c$ o número de colunas e I o número de linhas da imagem transformada em matriz. A evolução da peça através do tempo pode então ser calculada mediante as variações das alterações espaciais locais, partindo da imagem inicial ( $t=$ ano 0 ) utilizada como referência para outras de períodos temporais, permitindo a comparação entre elas. O passar do tempo irá provocar alterações morfológicas localizadas, sendo de esperar um aumento da entropia (variações das alterações espaciais locais) com o passar do tempo e, portanto, um aumento do VAM (ver figura 1). Para além de fornecer essas alterações em valores numéricos, o algoritmo proposto permite ainda visualizar a entropia de cada imagem através da delineação de um diagrama tridimensional (3D).

\section{- Entropia da imagem}

A entropia associada à teoria da informação foi desenvolvida por Claude Shannon (1948), com o intuito de estudar a quantidade de informação transmitida numa mensagem [figura 1]. Este conceito tem vindo a ser explorado por diferentes áreas de investigação científica, nomeadamente: no sector financeiro, para verificar o nível de informação de indicadores aplicados a demonstrações financeiras para o sector público de um país (AlmeidaSantos, Rocha, Hein 2014); nas ciências atmosféricas, com o estudo da precipitação pluvial (Medeiros et al. 2015); no âmbito da medicina, para o estudo de padrões de oscilações do cérebro (Baravalle, Rosso, Montani 2018); entre outros. É entendido como a medida da incerteza existente numa variável aleatória, em que valores altos dessa incerteza resultam no aumento da entropia (Pavão 2011:158). Numa imagem, a entropia pode ser calculada de várias formas, através da distribuição estatística dos pixéis, isto é, por exemplo pelo seu histograma de luminância, que consiste na contagem dos níveis cinza da imagem, fornecendo informação acerca da distribuição dos pixéis de acordo com os possíveis níveis de luminância, ou a partir do resultado de transformadas de Fourier (Esquef et al. 2003:5).

No algoritmo proposto, a função thresholding é usada para determinar o limite a partir do qual se considera existir uma alteração na variação morfológica,

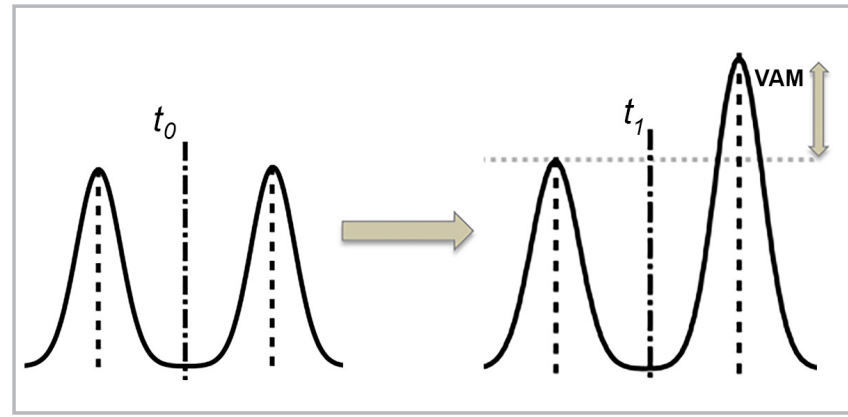

Figura 1.- Esquema ilustrativo do cálculo do valor de alteração morfológica (VAM) da entropia das imagens, onde o VAM representa a distância das alterações de picos do diagrama 3D, das imagens t0 e t 1 , correspondentes às alterações localizadas de luminância que se correlacionam com alterações morfológicas. Diagrama com menor entropia (esquerda) e com maior entropia (direita). @Ana Alvarez

permitindo estimar o valor de entropia. A imagem é transformada numa escala de cinzas e os valores de threshold das alterações de variações espaciais locais (entropia), superiores aos valores threshold da imagem de referência, são indicadores de áreas de potencial de corrosão. Assim, a entropia traduz-se na irregularidade que uma imagem pode apresentar durante o processo de medição da distribuição da variação dos tons cinza, provocada pelo relevo da textura da corrosão. Como representado na figura 2, quanto maior for a regularidade associada à variação dos tons cinza, variações abaixo do threshold, menor é a entropia indicando uma maior regularidade na distribuição da corrosão da superfície. Assim, mesmo existindo corrosão generalizada e uniforme, a comparação com a imagem original permitirá obter valores de threshold superiores ao permitido em toda a área de análise e, por isso, a corrosão generalizada pode ser detetada, apesar de localmente existir pouca variação de corrosão.

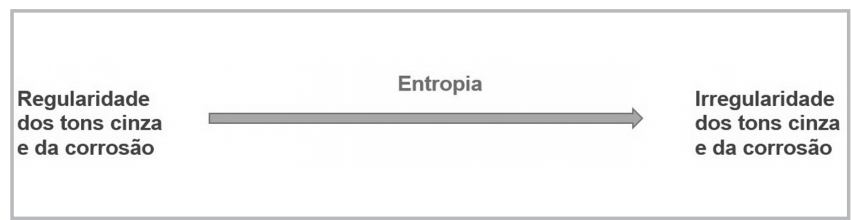

Figura 2.- Esquema do aumento da entropia de uma imagem de corrosão, conforme a irregularidade da corrosão. @Ana Alvarez

\section{Caso de estudo}

Como estudo de caso, a escultura de aço carbono de Gonçalo Jardim (ver figura 3) foi analisada pelo sistema PID, no contexto da Conservação e Restauro, para analisar, documentar e monitorizar a evolução da morfologia da corrosão do material no decorrer do tempo. Numa entrevista realizada com o artista, em Março de 2017, compreendeu-se que essa oxidação natural da liga é considerada fundamental no conceito da obra, uma vez que a questão da autenticidade e da veracidade dos materiais é lhe absolutamente determinante. A 
obra, datada de 2014, tem de dimensões $202 \times 35 \times 19 \mathrm{~cm}$, encontra-se exposta às condições climáticas da zona de São Miguel de Machede (Évora, Portugal) e apresenta corrosão uniforme no material. Évora classifica-se como uma zona parda, submaritima, pertencente a uma região atlântica com influência mediterrânica que se traduz num clima temperado seco, com a temperatura do mês mais quente do verão superior a $20^{\circ} \mathrm{C}$ (Almeida, Elisabete e Ferreira 1998:265). No gráfico 1, estão registados os valores médios da temperatura máxima e mínima do ar $\left({ }^{\circ} \mathrm{C}\right)$ e da humidade relativa do ar (\%), do ano de 2018, para a zona de Évora. De acordo com os registos, trata-se de uma zona que apresenta valores de temperatura e de humidade relativa variáveis que, segundo a normalização ISO 9223 (2010), classifica-se como um ambiente seco e frio, que expressa um grau de corrosividade atmosférica baixo (C2).

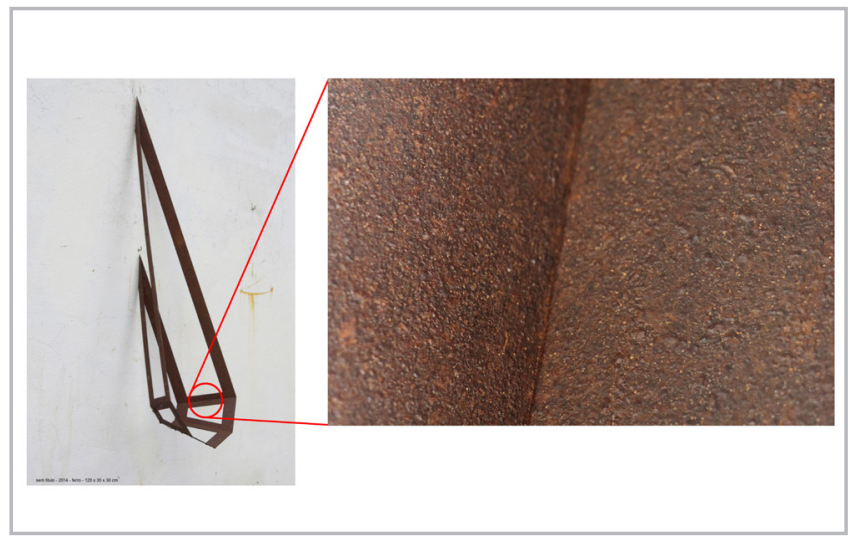

Figura 2.- Escultura em aço (2014) de dimensões $120 \times 35 \times 30 \mathrm{~cm}$ (esquerda), com pormenor da pátina (direita). @Gonçalo Jardim e Ana Alvarez.

\section{Metodologia}

Para testar a veracidade do algoritmo, realizou-se uma simulação através de fotografias de uma das superfícies de uma amostra, de substrato metálico, recolhida da obra.

Para o processamento do algoritmo foi utilizado um Macbook Pro (13-inch, late 2011) de 64 bits com um processador Intel Core i5 a 2,4 GHz, uma placa gráfica Intel HD Graphics 3000 com 512 MB, uma memória de 8 GB de SDRAM DDR3 a 333MHz e um sistema operativo MacOS El Capitan (10.11.4). A versão do MatLab ${ }^{\circledR}$ foi a R2017b (9.3.0) de 64 bits.

No que concerne ao registo fotográfico da morfologia da corrosão, foram recolhidas duas imagens, da mesma zona de análise, em Junho de 2017 ( $\mathrm{t}=$ ano 0) e em Setembro de 2018 ( $\mathrm{t}=$ ano 1), por meio de uma câmara digital Panasonic DMC-TZ7, a uma distância focal de 8.5 mm, com ISO 320 e tempo de exposição 1/40 em f/3.8. Estas foram adquiridas no laboratório, num espaço interior fechado, com a câmara em suporte manual e utilizando a iluminação artificial da sala (lâmpada PHILIPS $^{\circledR}$ fluorescente TL-D 36W/840 de cor branco frio) a que a amostra estava sujeita.

As imagens foram sobrepostas e ajustadas proporcionalmente no tamanho, através da opção 'Restringir proporções' da ferramenta 'Tamanho de Imagem' do programa AdobePhotoshop ${ }^{\circledR}$ CC 2017. As duas imagens foram alinhadas, de forma a corresponder os pixéis, para confirmar a coincidência da representação fotografada, sendo posteriormente gravadas em formato JPEG, com as dimensões $825 \times 1469$ pixéis.

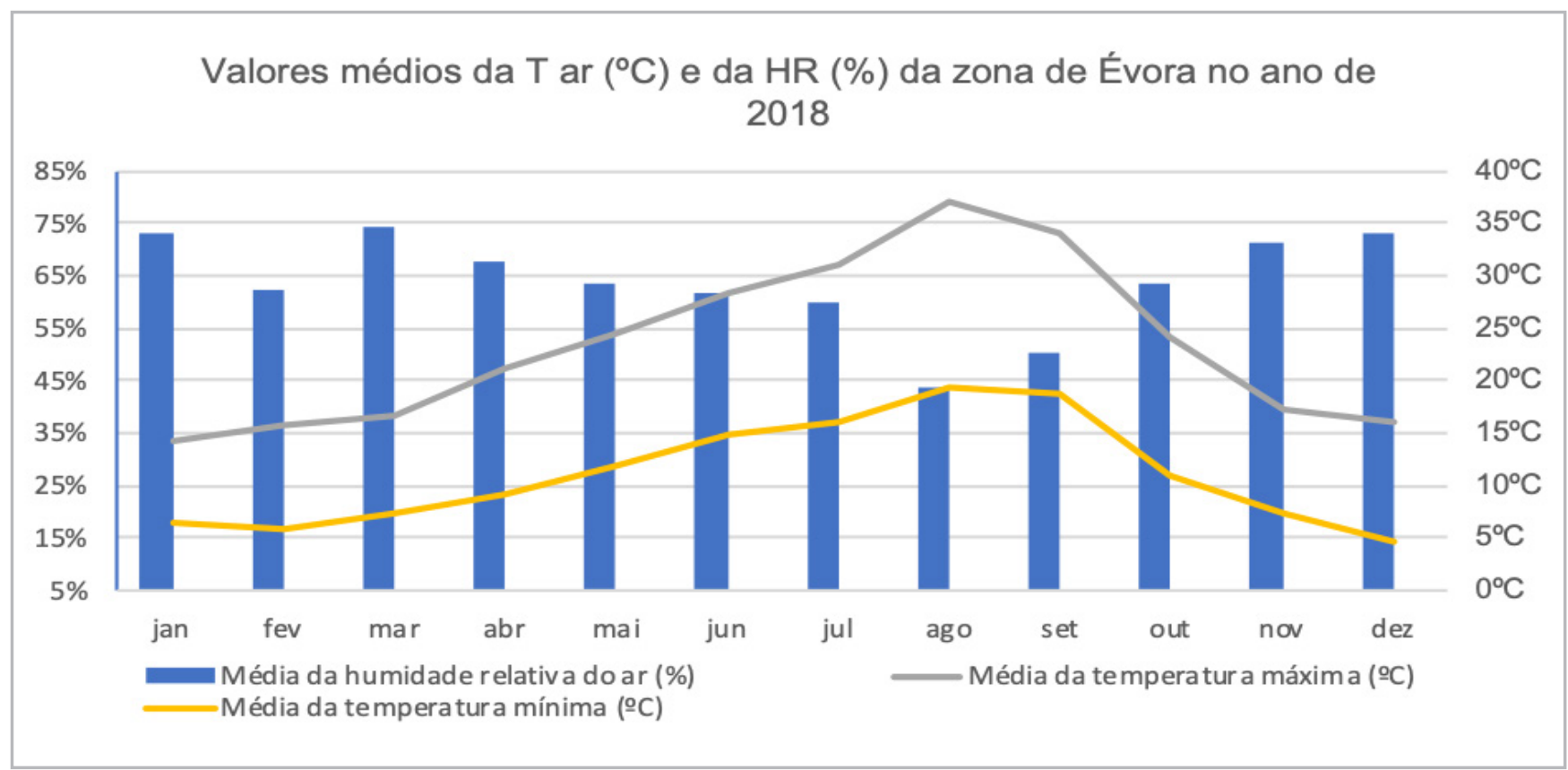

Gráfico 1.- Valores médios da temperatura máxima e mínima do $\operatorname{ar}\left({ }^{\circ} \mathrm{C}\right)$ e da humidade relativa do ar (\%), do ano de 2018 , para a zona de Évora 

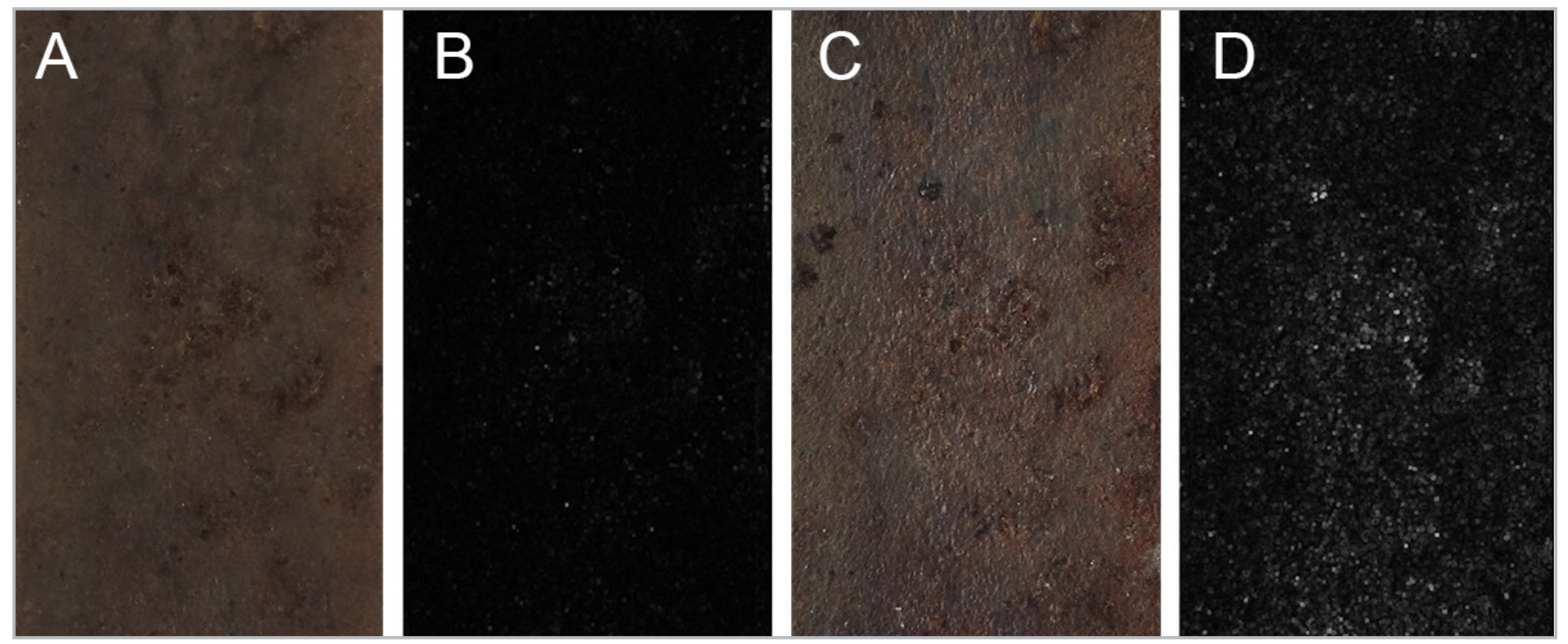

Figura 4.- Imagem da superfície corroída de Junho de 2017 (A), da zona mais exposta às condições climáticas, com a respetiva imagem binária à direita (B), e imagem da superfície corroída de Setembro de 2018 (C), com a respetiva imagem binária à direita (D), onde a entropia é representada pelos tons mais claros das imagens B e D.

No algoritmo proposto, o cálculo do VAM dividiu-se em dois momentos: 1) análise da aquisição fotográfica de referência e 2) análise comparativa entre o registo fotográfico de referência e o de após um ano de exposição. As imagens foram introduzidas no algoritmo e processadas em imagens de escala de níveis cinza. Foram transformadas em imagens de textura, onde os valores de entropia de cada pixel foram calculados em função dos pixéis adjacentes, numa área de $9 \times 9$ pixéis. A opção por utilizar uma pequena área para comparação em detrimento da utilização de pixéis individuais, deve-se à irregularidade da corrosão do aço, onde, por comparação com a original seria impossível garantir a correspondência entre pixéis equivalentes. A utilização de uma pequena área permite comparar a média da área com a área equivalente, o que facilita a comparação. A partir destas, procedeu-se ao thresholding das imagens, que foram convertidas em escala binária (ver figura 4, B e D). Posteriormente, o algoritmo delineou diagramas tridimensionais da representação da entropia de cada imagem e calculou o VAM a partir das imagens binárias. Ou seja, para cada área comparou-se o $\mathrm{J}$ e o / e calculouse o valor médio absoluto da entropia de cada imagem, sendo que a variação deste valor significa que há diferença nas imagens e, consequentemente, mudanças na irregularidade da corrosão.

\section{Resultados e discussão}

No cálculo do valor de alteração morfológica da imagem de referência, introduziu-se a imagem de $\mathrm{t}=$ ano 0 no algoritmo desenvolvido em MatLab ${ }^{\oplus}$, onde $J_{r \mid}$ e $I_{r l}$ foram a mesma imagem, e, tal como previsto, não revelou nenhuma alteração morfológica, resultando num VAM = 0 . No estudo comparativo da imagem de referência $(t=$ ano 0$)$ e da imagem de após um ano de exposição ( $t=$ ano 1), analisou-se a entropia de cada imagem, no qual verificou-se que as imagens são diferentes, havendo uma maior irregularidade dos tons cinza da imagem $t=$ ano 1 (ver figura 4, D), e calculou-se o valor médio absoluto da entropia das duas imagens, que resultou num VAM $=0.0898$. Isto significa que, no espaço de um ano, e de acordo com as imagens obtidas, houve alteração na morfologia da corrosão e, portanto, um aumento da entropia que, ao representar a variação da imagem binária no diagrama 3D, resultou num aumento do ruído (variação e intensidade) dos picos (ver figura 5).

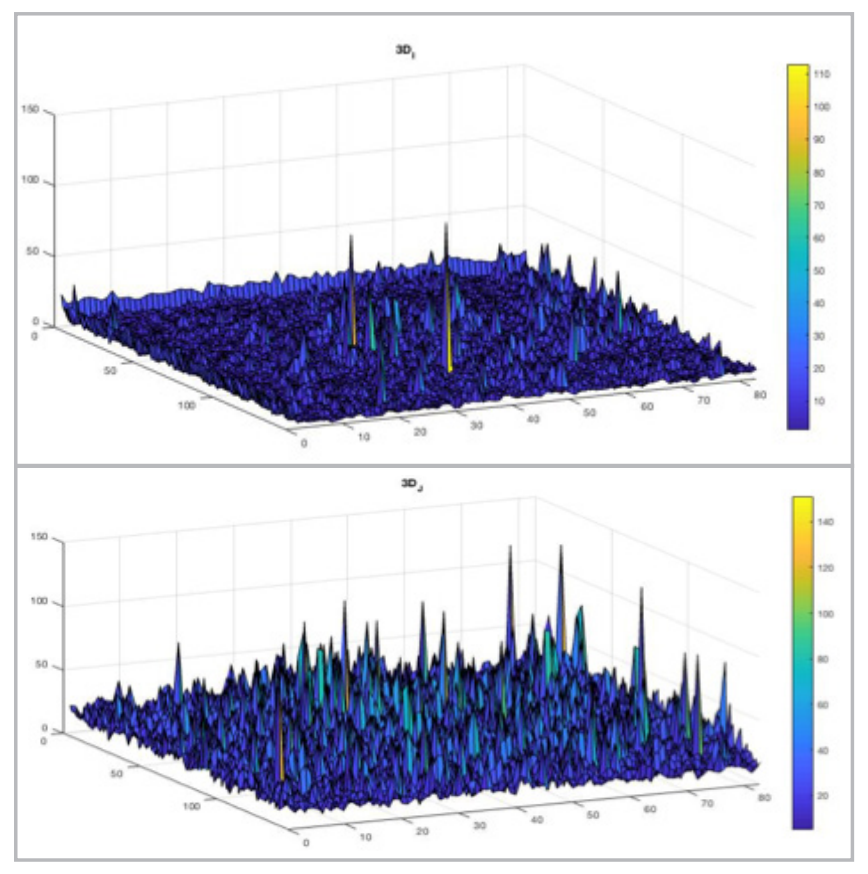

Figura 5.- Representação tridimensional da entropia da imagem de referência (acima) e da imagem de após um ano de exposição (em baixo), onde quanto maior é a entropia, maior é o ruído (variação e intensidade) dos picos do diagrama. @Ana Alvarez João Linhares. 
Com base nos resultados obtidos com o algoritmo proposto, verificou-se que o PID é uma ferramenta que possibilita o acompanhamento da deterioração do material no decorrer do tempo. Através do cálculo do VAM podemos constatar que, após um ano de exposição às condições climáticas, houve alterações da morfologia e, portanto, um aumento da entropia, que se traduz em maior irregularidade dos tons de cinza da imagem. Este resultado pode ser correlacionado com a superfície analisada, permitindo avaliar alterações localizadas e generalizadas da área corroída.

Pelo fato deste algoritmo ainda não ter sido aplicado, anteriormente a esta investigação, para a monitorização dos produtos de corrosão, não existem escalas onde se possa quantificar o grau de alteração com base nos valores VAM. Nesta fase, embora o VAM seja um valor numérico, esta variável fornece uma informação mais qualitativa do que quantitativa, uma vez que qualquer que seja o valor acima de zero significa que há alteração da morfologia (VAM $=0$ sem alteração; VAM > 0 - com alteração). Serão necessários mais ensaios para se conseguir traçar intervalos numéricos em relação ao VAM.

Tendo em consideração que os resultados foram obtidos no período académico afeto à dissertação, de um ano letivo, apenas se percebe que houve alteração morfológica. Pretende-se explorar este tema em projetos futuros.

\section{Conclusão}

Esta investigação está em curso. Os resultados obtidos através do método testado de processamento de imagem digital revelaram que, após um ano, houve alteração da morfologia e, portanto, um aumento da entropia, que se traduziu em maior irregularidade dos tons de cinza e consequentemente da superfície corroída.

A metodologia empregue neste estudo e os resultados são um estudo piloto, e como tal há várias tarefas do processo a serem melhoradas, nomeadamente na fase de registo fotográfico. Pelo mesmo motivo, também não é possível apresentar dados comparativos que indiquem o grau de corrosividade da liga da obra de Gonçalo Jardim.

A continuação deste estudo passaria por uma aquisição fotográfica mais controlada, recorrendo a calibração ou correção colorimétrica das imagens obtidas de acordo com a iluminação e uma monitorização anual da corrosão através do valor VAM, de modo a verificar se há estabilização ou aumento de VAM das imagens entre os anos, e, neste último caso, em que proporção, e criar uma escala que quantifique o grau de alteração da corrosão com base nos valores VAM.

A utilização de condições ótimas e reprodutíveis de aquisição de imagem poderão potenciar o registo digital e posterior análise do VAM, assim como a sua parametrização e escalonamento para obtenção de uma futura escala comparativa.
No caso de ser feita alguma intervenção de conservação e restauro para reduzir ou prevenir o avanço do processo de corrosão da obra, esta metodologia pode servir ainda para testar a eficácia desse tratamento, fazendo várias análises temporais da morfologia da corrosão após a realização dessa ação.

Poderá ser feito ainda um estudo paralelo, em que a mesma amostra é submetida a diferentes atmosferas, calculando para cada uma delas os respetivos VAM's, de modo a confirmar o tipo de atmosfera mais aconselhável, consoante o artista pretenda um eventual atraso ou aceleração da corrosão. Outra finalidade importante, deste último ponto mencionado, é a oportunidade de compreensão do comportamento da mesma obra em ambientes diferentes.

Embora o estudo esteja centrado na monitorização da evolução da corrosão, este algoritmo também permite avaliar alterações de outras superfícies além das metálicas.

\section{Referências}

ALBUQUERQUE, M. P., ALBUQUERQUE, M. P. (2001). Processamento de Imagens: Métodos e Análises. Rio de Janeiro: FACET

ALMEIDA-SANTOS, P. S., ROCHA, I., HEIN, N. (2014). "Utilização da entropia informacional na seleção de indicadores financeiros mais relevantes para a tomada de decisão no sector público: o caso dos estados brasileiros". Perspectivas em Ciências da Informação, 19:83105. https://doi.org/10.1590/1981-5344/1780. [Consult. 7/12/2018]

ALMEIDA, M. E. M., FERREIRA, M. G. S. (1998). Corrosão Atmosférica: Mapas de Portugal. Lisboa: INETI/IMP/LTR.

ASM International (2000). Corrosion: Understanding the Basics. Ohio: ASM International.

BARAVALLE, R.; ROSSO, O.A.; MONTANI, F. (2018). "Casual ShannonFisher Characterization of Motor/Imagery Movements in EEG", Entropy, 20:660-678. https://doi.org/10.3390/e20090660. [Consult. 7/12/2018]

BENTO, M. P. et al. (2009). Image processing techniques applied for corrosion damage analysis. https://www.researchgate.net/ publication/228937062 Image processing techniques applied for corrosion damage analysis. [Consult. 3/12/2018]

CHOI, K. Y., KIM, S. S. (2004). "Morphological analysis and classification of types of surface corrosion damage by digital image processing", Corrosion Science, 47:1-15. https://doi.org/10.1016/j. corsci.2004.05.007. [Consult. 3/12/2018].

DIAZ, J. et al. (2017). "Rust detection using processing via Matlab". En Conference TENCON. Malaysia:Tencon, 1327-133. https://doi.org/ 10.1109/TENCON.2017.8228063. [Consult. 9/12/2018]

ESQUEF, I.A. et al. (2003). Processamento Digital de Imagens. Brasil: Centro Brasileiro de Pesquisas Físicas, 1-12, http://www.cbpf.br/cat/ pdsi/pdf/cap3webfinal.pdf. [Consult. 9/12/2018] 
GHANTA, S. et al. (2011). "Wavelet domain detection of rust in steel bridge images". En 2011 IEEE International Conference on Acoustics, Speech and Signal Processing (ICASSP), Prague: ICASSP, 1033-1036. $\quad$ https://doi.org/10.1109/ICASSP.2011.5946583. [Consult. 3/12/2018]

ISO/DIS 9223 (2010). "Corrosion of metals and alloys" En Corrosivity of atmospheres - Classification, determination and estimation, Geneva: ISO/TC 156 WG4.

MATHWORKS, INC (2005). MATLAB: The language of technical Computing. Getting started with MATLAB, 7, Natick MA: MathWorks. $\quad$ https://www.csd.uoc.gr/ hy215/tutorials/ GetStartWithMATLAB.pdf. [Consult. 9/9/2018]

MEDEIROS, R.M. et al. (2015). "Aplicação da teoria da entropia no estudo da precipitação pluvial em Teresinha-Pi", Revista de Geografia (UFPE), 32:2:206-218. https://periodicos.ufpe.br/ revistas/revistageografia/article/view/229164/23565. [Consult. 7/12/2018].

PAVÃO, R. (2011). Entropia informacional e aprendizagem de sequências. São Paulo: Tese de Doutoramento, USP/ Instituto de Biociências. http://www.teses.usp.br/teses/ disponiveis/41/41135/tde-21092011-135012/pt-br.php. [Consult. 9/9/2018]

SHANNON, C. E. (1948). "A Mathematical Theory of Communication", The Bell System Technical Journal, 27:3:379423. https://doi.org/10.1002/j.1538-7305.1948.tb01338.x. [Consult. 9/9/2018]

YIDONG, Z. et al. (2017). "A non-destructive approach using MatLab software for morphology analysis of ancient mural deterioration", Studies in Conservation, 62:7:384-392. https:// doi.org/10.1080/00393630.2016.1183864. [Consult. 7/9/2018]

\section{Autor/es}

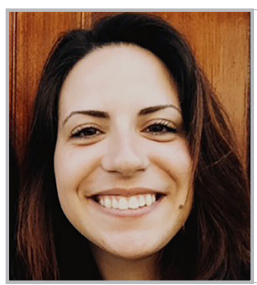

\section{Ana Sofia Alvarez}

ana_alvarez_279@hotmail.com

Faculdade de Belas Artes da Universidade de Lisboa, FBAUL/CIEBA

Licenciatura em Artes Visuais - Multimédia, na vertente de escultura, com especialização em metais, pela Escola de Artes da Universidade de Évora, Évora, Portugal (2014). Mestrado em Ciências da Conservação, Restauro e Produção de Arte Contemporânea, pela Faculdade de Belas Artes da Universidade de Lisboa, Lisboa, Portugal (2018). A pesquisa de mestrado foi sobre a monitorização da corrosão atmosférica de ligas ferrosas, através do método de processamento de imagem digital.
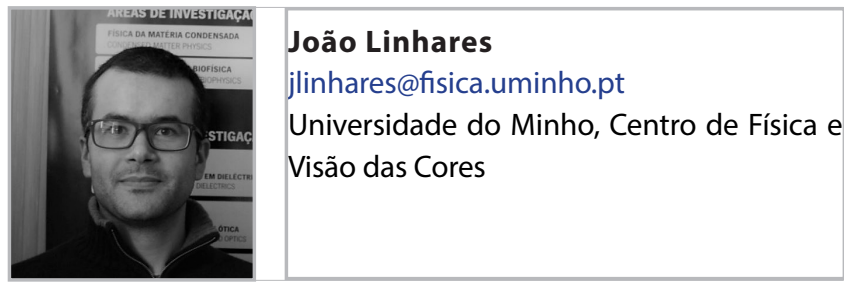

Licenciatura em Optometria e Ciências da Visão pela Universidade do Minho, Braga, Portugal (2002). Em 2006 obteve o grau de MPhil em Optometria e Neurociência pela Faculty of Life Sciences of the University of Manchester, Manchester, Reino Unido. De volta à Universidade no Minho, continuou a sua investigação e formação, obtendo o Doutoramento em Ciências pela Escola de Ciências da Universidade do Minho em 2011. De Março de 2011 a Julho de 2012 foi Lecturer, e de Agosto de 2012 a Agosto de 2013 foi Senior Lecturer, no departamento de Vision and Hearing Sciences, na Anglia Ruskin University, Cambridge, Reino Unido. Em Julho de 2013 obteve o estatuto de Fellow da Higher Education Academy após a conclusão com sucesso da pós-graduação em Learning and Teaching (Higher Education) atribuída pela Anglia Ruskin University, Cambridge, UK. Atualmente é Professor Auxiliar no Departamento de Física da Universidade do Minho.

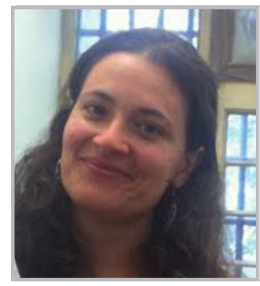

Ana Bailão
ana.bailao@gmail.com
Faculdade de Belas Artes da Universidade
de Lisboa, FBAUL/CIEBA; (CITAR) da
Universidade Católica, C. R. do Porto

Licenciatura em Conservação e Restauro pelo Instituto Politécnico de Tomar, Tomar, Portugal (2005) e mestrado em Pintura Conservação pela Universidade Católica Portuguesa, Porto, Portugal (2010). A pesquisa de mestrado foi sobre metodologias e técnicas de retoque. Doutoramento em Conservação de Pinturas na mesma universidade, em colaboração com o Centro de Investigação em Ciência e Tecnologia das Artes (CITAR) e com o Instituto do Património Cultura de Espanha (IPCE), em Madrid. A pesquisa de doutoramento foi sobre os critérios e metodologias que podem ajudar a melhorar a qualidade do retoque da pintura. Desde 2004 que realiza trabalhos de conservação e restauro. Desde de 2008 que tem trabalhado como docente de conservação e restauro, trabalhando atualmente na Faculdade de Belas Artes da Universidade de Lisboa, como docente do Departamento de Ciências da Arte e do Património.
Artículo enviado el 09/12/2018 Artículo aceptado el 08/03/2020

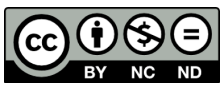

https://doi.org/10.37558/gec.v17i1.614 